\title{
Entregando-se aos dados: programática de uma etnografia vivaz
}

Gabriel Banaggia ${ }^{1}$

\section{Resumo}

Levando em conta os diagnósticos do movimento pós-moderno na antropologia, este artigo se dedica a pensar estratégias para a realização de trabalho de campo e a subsequente redação de etnografias na contemporaneidade. Para tanto, procura enfrentar as críticas a respeito da autoria e da autoridade etnográficas ao mesmo tempo de modo a encará-las em sua justeza e a não ser paralisado por elas. Busca-se assim reconceber o que se imaginariam ser os contornos de uma hierarquização de outro modo incontornável, por meio da consideração de um tipo de todo que não unifica as partes em questão, a saber, as partes envolvidas numa pesquisa antropológica, em geral pessoas. Em vez de apostar em processos sintéticos de totalização, trata-se aqui de levar em consideração certos todos singulares que podem ser dispostos também como partes interessadas do processo de pesquisa, dispondo-se ao lado e não acima das demais. 0 trabalho etnográfico surge assim não como algo eminentemente unilateral, mas como envolvendo uma série de prestações específicas. 0 s dados da pesquisa figuram justamente algo que é dado a alguém, por alguém: pragmaticamente, em circunstâncias que não se pode abstrair a priori. As práticas discursivas e não discursivas de que a pesquisa é feita são assim suscitadas em conversação e troca, podendo ser evocadas, de maneiras distintas, no trabalho de campo e na redação etnográfica. São mobilizados exemplos concretos para o desenvolvimento do argumento, extraídos tanto da literatura acadêmica quanto de pesquisa própria realizada no campo das religiões de matriz africana no Brasil.

\section{Palavras-chave}

Trabalho de campo. Etnografia. Religiões de matriz africana.

\section{Abstract}

Considering the diagnoses of the postmodern movement in anthropology, this article focuses on strategies for carrying out the fieldwork and for the subsequent writing of contemporary ethnographies. To this end, it aims to engage the critic theories on authorship and ethnographic authority while doing them justice, and not being paralyzed by them. This article seeks to reconceive what would be the contours of an otherwise inescapable hierarchy by considering a kind of whole that does not unify the parts in question, namely, the parties involved in an anthropological

\footnotetext{
1 Doutor em Antropologia no Museu Nacional pela Universidade Federal do Rio de Janeiro; desenvolve pesquisa de pós-doutorado no Programa de Pós-Graduação em Ciências Sociais da PUCRio.E-mail: gbanaggia@gmail.com
} 
investigation, who are generally people. Instead of betting on synthetic totalization processes, this text proposes the consideration of specific singular wholes that can also be displayed as interested parties in the research process, next to and not above the others. The ethnographic work thus emerges not as something eminently unilateral, but as something that involves a number of specific requitals. The research data represents exactly something that is given to someone by someone: pragmatically, in circumstances that cannot be a priori abstracted. The discursive and non-discursive practices that compose the research are thus elicited in conversation and exchange, able of being evoked in different ways in the fieldwork and the ethnographic writing. Concrete examples are mobilized for the development of the present argument, drawn both from academic literature and the research conducted in the field of African-based religions in Brazil.

\section{Keywords}

Fieldwork. Ethnography. African-based religions.

“Há duas fases bem distintas num pôr-do-sol. No início, o astro é arquiteto. Só depois (quando seus raios chegam refletidos e não mais diretos), transforma-se em pintor. Assim que se esconde atrás do horizonte, a luz enfraquece e faz surgir planos a cada instante mais complexos. A luz plena é inimiga da perspectiva, mas, entre o dia e a noite, há lugar para uma arquitetura tão fantasista quanto temporária.

Claude Lévi-Strauss (1955: 63)

As obras de caráter fantasista e temporário a que se refere a epígrafe deste artigo são tão sólidas quanto ficcionais e recebem o nome de etnografias. Gênero narrativo característico da antropologia, a etnografia é a princípio inseparável da prática que caracteriza de maneira mais inequívoca a disciplina: o trabalho de campo. Este texto se dedica a refletir a respeito dessas duas atividades, considerando a pesquisa e o relato subsequente a ela como processos mutuamente constituídos. Ao se indagar a respeito das formas pelas quais a antropologia tem se dedicado a registrar as experiências vividas, recebem especial atenção os modos de se levar em conta os diferentes saberes em jogo na interação entre as pessoas que ocupam diferencialmente, e por vezes de maneira reversível, posições nativas e antropológicas.

Em vez de lidar com grandes narrativas de desenvolvimento histórico, a proposta mais restrita deste texto procura se fundamentar em um piso mais movediço, como sugere James Clifford (1986: 24 e nota 13), ou no solo firme de areias instáveis, no dizer de Bruno Latour (2005: 24). Trata-se assim de uma reflexão experimental que almeja propor estratégias pontuais para contribuir com a ideia 
de se manter, até o limite do possível, a maior continuidade que for possível entre o trabalho de campo e o relato etnográfico, entre as maneiras pelas quais ambos se afetam, ainda que retrospectivamente. Dito de outro modo, a proposta é arriscar fornecer instrumentos para que se pense a etnografia, qual resume Ferrari (2006), como algo poroso, fractal, vivaz ${ }^{2}$. Como a autora propõe, baseada na obra de Roy Wagner:

A ética e as metodologias do trabalho de campo deveriam tornar-se "transparentes" para a criatividade sob estudo. Deveríamos subordinar suas pressuposições e preconcepções à inventividade dos "povos estudados" de modo a não esvaziar previamente sua criatividade no interior de nossa própria invenção. (FERRARI, 2006, ênfase no original).

Há quem diga que tentar refletir de forma excessivamente detida sobre o trabalho de campo seria uma tarefa de saída condenada à esterilidade: afinal de contas, tendo em mente o parecer de Paul Radin, relatado por Evans-Pritchard (1937: 243), ninguém sabe muito bem como faz o próprio trabalho de campo. No entanto, isso nunca significou que se deixasse de inquirir a respeito dele, sendo esse próprio experimento conceitual justamente mais um dos muitos e recorrentes inícios do trabalho de campo em si. Negá-lo seria, afinal de contas e de certo modo, o mesmo que considerar como absolutamente apartados, por um lado, o trabalho de campo e as leituras que o balizam, ou ainda, por outro lado, a prática e a teoria antropológicas. Disjunções dessa ordem não serão aqui consideradas pertinentes ${ }^{3}$.

Quando se aceita, assim, esta proposta, é útil se passar à consideração do solo específico que se pretende investigar, em função do que Richard Fardon (1990: 23), referindo-se a uma preocupação ampla, censura:

Paradoxalmente, esta preocupação com a etnografia é etnograficamente inespecífica. Ela nos convida a sacrificar a especificidade da pesquisa em locais particulares em momentos determinados para tratar toda a pesquisa como um certo número de refrações de um processo etnográfico mestre. Reflexividade, no sentido de autoanálise da experiência do trabalho de campo, se torna o processo de relacionar a etnografia entre outrem à "Etnografia do Outro".

\footnotetext{
${ }^{2}$ Em botânica, vivaz é o termo que designa plantas que podem desenvolver rizomas em vez de raízes.

${ }^{3}$ Sobre os motivos para que se considerem sempre essas justaposições, ver, por exemplo, Viveiros de Castro (2002: 123), para a primeira, e Evans-Pritchard (1937: 243); Fardon (1990: 28); Sanjek (1990: 198), para a segunda.
} 
Ainda que essa busca por especificidade possa ser vista como função de uma "síndrome de individualismo romântico", tendo como efeito a criação de "identidades profissionais" (JACKSON, 1990: 19), prefere-se aqui considerá-la como constitutiva do fazer etnográfico, já que uma forma de concebê-lo é como sendo um processo necessariamente transformado, no dizer de Mead (1933: 9), de acordo com as diversas culturas que se pretende estudar. Mais ainda, até: não se trata de utilizar um único e mesmo método, tido como propriamente antropológico, lapidado de acordo com as diferentes realidades a que se tem acesso, mas de considerar as próprias problemáticas como radicalmente diversas (VIVEIROS DE CASTRO, 2002: 117, 122, 126). Ou seja, trata-se de pensar não em uma metalinguagem universalmente aplicável a priori, mas em uma espécie de "infralinguagem", no sentido que Bruno Latour $(2005: 30,49)$ confere à expressão: uma ferramenta cuja função é simplesmente auxiliar a prestar atenção às metalinguagens plenamente desenvolvidas das próprias pessoas. Com isto desejase, ativamente, não restringir de antemão as questões a um recorte específico, e sim permitir que elas emerjam a partir da etnografia - daí instar-se frequentemente os antropólogos a anotarem tudo o quanto for possível, já que é só retrospectivamente que se saberá o que poderá ser útil para a pesquisa (STRATHERN, 1999: 9). É justamente por conta disto que este artigo procura se fazer acompanhar sobremaneira de exemplos derivados da literatura que se dedica às religiões de matriz africana, área em que o autor concentra sua pesquisa empírica.

\section{Autoria, autoridade}

Após o movimento do pós-modernismo antropológico, sistematizado pelo "conjunto de 1986", na expressão de Nicholas Thomas (1991: 318 nota 3), tornouse praticamente incontornável abordar as questões tanto a respeito da autoria como da autoridade dos textos etnográficos; por vezes, como já se fizera anteriormente, mesmo da etnografia como um todo. Primeiramente, pretende-se aqui estabelecer distância de uma alternativa imputada a determinados autores tidos como pósmodernos. Ela parte da ideia de que, depois da crítica ao ponto de vista do antropólogo onipresente e intangível, que vê sem ser visto, tudo o que restaria ao autor seria dobrar-se sobre si mesmo, tergiversando antes de tudo a respeito do que acontece consigo próprio em função do trabalho de campo ${ }^{4}$. Essa visão imagina que, em função de o objeto não mais ser concebido como transparente, tem

\footnotetext{
${ }^{4}$ Um dos exemplos mais marcantes dessa tendência é o livro de Paul Rabinow (1977), publicado dois anos após o surgimento de sua etnografia no Marrocos.
} 
por missão falar daquilo que ainda seria passível de cognoscibilidade: o sujeito. Todavia, como advertem trabalhos como os de Clifford (1986: 26) e Strathern (1991: 15, 108-109), essa é uma alternativa que continuaria sendo inviável: o subjetivismo não é saída porque o sujeito em si tampouco é translúcido. Ainda que falar de si na relação com o outro seja inevitável, concorda-se, não escapar em alguma medida de si mesmo significaria falhar no trabalho etnográfico.

Afiguram-se ainda outras opções. Adicionando pontos de vista, seria o caso de imaginar a obtenção de um retrato mais completo da realidade, empreitada grande demais para uma única pessoa. Apesar da existência de pareceres contrários, como declararam, por exemplo, William Rivers (apud STOCKING, 1983: 92) e Edward Evans-Pritchard (1937: 251), a vontade de se dedicar a obras etnográficas coletivas atravessa alguns antropólogos. Mais especificamente, a ideia de se reunir conjuntos de pessoas em equipes de pesquisa surge como modelo alternativo no dizer de Stocking (1983: 79). Ela surge, por exemplo, como desejo para Clifford Geertz (1973: 428 nota 15), na experiência coletiva de Maurice Leenhardt (identificada por CLIFFORD, 1981: 229-230), nos times de observadores de Michel Griaule (apud CLIFFORD, 1983: 135-136) ou Oscar Lewis (apud SANJEK, 1990: 231). A equação pareceria simples: quanto mais profissionais na pesquisa, mais conhecimento gerado.

Embora não se ignore o valor que pode existir na troca de métodos, tecnologias ou mesmo notas de campo entre antropólogos, à maneira das ciências exatas, sugerida, por exemplo, pelos entrevistados de Jean Jackson (1990: 9, 26), não se imagina aqui que a resposta à questão seja de todo quantitativa, mas de certa maneira qualitativa. Difere-se então ao menos parcialmente do pós-modernismo assim caracterizado, que imaginaria ser seu dever adicionar multiplicidade a um mundo dominado por grandes narrativas: a multiplicidade, afirma, por sua vez, a teoria-ator-rede (LATOUR, 2005: 116 nota 165), não é prerrogativa de seres humanos a interpretar as coisas do mundo, mas propriedade das coisas em si. Sendo assim, lidar com essa multiplicidade constitutiva mostra-se um imperativo, em especial quando se trabalha com religiões como o candomblé, que a tematiza de diversas formas (cf. GOLDMAN, 2005).

Seria, então, o caso de estender a autoria dos relatos que se produz àqueles de que se fala a respeito (CLIFFORD, 1986: 7)? Esta pode ser, inclusive, também uma forma de se ser menos autoritário na representação que deles se faz. Não se nega que possa haver empreendimentos em que nativos apresentam-se como verdadeiros coautores (CLIFFORD, 1981: 240-242, 248) - ainda que não pareça tão automático o deslizamento de escritor de transcrições míticas ou participante em coletânea de livros para autor de monografia etnográfica -, e que assim se pode 
colocar em relevo o caráter processual da cultura. Textos expandidos desta forma, em dispersão, não se deixariam resumir em um somatório totalizante (ou autossuficiente), evidenciando que o que se pretende representar é um momento particular de produção etnográfica (CLIFFORD, 1986: 15-16). Ainda que se concorde aqui plenamente com essa segunda proposição, a proximidade entre os dois argumentos não deveria impedir que sejam postas ressalvas à primazia da autoria compartilhada. Constate-se o que se lê em Clifford (1986: 17, ênfase adicionada):

Uma vez que os informantes comecem a ser considerados como coautores, e o etnógrafo como escriba e arquivista bem como observador interpretante, podemos colocar questões novas e críticas para todas as etnografias. Por mais monológica, dialógica ou polifônica sua forma, elas são arranjos hierárquicos de discursos.

Assim, de que modo reconceber o que se imagina ser uma hierarquia incontornável? Pelo que afirma Clifford, a hierarquia seria efeito da parcialidade inevitável dos registros, de sua fragmentalidade inerente, tornando-se menos totalizável quanto mais discursos se adiciona ao registro. Contudo, como aponta Strathern (1991: 109), a ideia de que só se pode partir de fragmentos não elimina por si só a possibilidade da existência do todo, pelo contrário até: pensa-se sempre em fragmentos recortados de uma totalidade anterior, ainda que inalcançável (e por vezes tido como acessível num passado histórico). Do mesmo modo, continua a autora, nem todo texto precisa resultar num todo, sendo possível justapor narrativas incomensuráveis entre si, dispondo parcialmente elementos díspares (STRATHERN, 1991: 109-110). Para que relações sejam concebidas em termos propriamente diferenciais, elas não devem ser analisadas em termos de círculos concêntricos, hierarquizantes e atemporais, sustenta Tânia Lima (1999: 48). Apoiando-se na filosofia de Deleuze e Guattari, essa autora sugere que aquilo que chama de ponto de vista do todo em regimes contra-hierárquicos permite conceber um tipo de todo que não unifica as partes, dispondo-se como uma parte entre outras e ao lado delas, não acima. Toda parcialidade, assim, pode ser vista como diferencialmente produtiva, em vez de inerentemente insuficiente.

A polifonia e o dialogismo, valorizados como modos de produção textual, notese, são dispositivos acionados para colocar em questão a autoridade monopólica de uma ciência desejosa de representar os outros (das mais diferentes formas e com os mais distintos objetivos), afirma Clifford (1986: 15). Atualmente, esse autor continua, a antropologia não pode mais falar com autoridade automática em nome de povos que não eram capazes de dizer nada a respeito de si mesmos, já que agora 
eles se encontram imersos em sistemas mundiais nos quais os próprios etnógrafos estão também implicados (CLIFFORD, 1986: 10). Se deste modo questiona-se a representação autoritária, oferecendo como alternativa uma representação ampliada derivada de uma nova situação histórica, esse diagnóstico pouco se faz para perturbar a ideia de representação em si. Além disso, não se imagina, para o presente texto, que a alteração deva se dar simplesmente em função de um novo contexto, mas que ela sempre foi possível quando se parte de uma alternativa conceitual distinta. Assim, seria possível afirmar que jamais foi categoria antropológica necessária o imperativo de representação de quem quer que seja, estando presente "sistema mundial" ou não (SAHLINS, 1985: viii; SAHLINS, 1995: 19). Portanto, a questão da consideração de nativos tanto como coautores de uma etnografia quanto como sujeitos a serem representados deve permanecer em aberto (cf. STRATHERN, 1987). Além disso, dá-la por resolvida de saída faz com que se corra o risco de se responder rápido demais a outra inquietante fonte de investigação, qual seja: que interesse podem ter determinados coletivos para suportar terem um etnógrafo ao seu lado, se é que há algum? As motivações nativas, muitas vezes, passam bem longe de ter nomes impressos na capa de livros.

O viés antropológico de denúncia do colonialismo não pode ser afastado com um golpe de mão, mas tampouco se deve aceitar que a diferença entre as posições de etnógrafo e de nativo seja sempre a de uma disposição hierárquica, e ainda por cima com o pesquisador no polo superior. Por vezes, assim, a impressão que se tem é justamente a inversa: é o antropólogo, diz Evans-Pritchard, o possuído pelo nativo (1937: 254). Neste sentido, Viveiros de Castro (1992: 180) diz não se iludir com a ideia de que há coautores para seu livro:

Os Araweté não me deram esta intimidade, de tratá-los como "sujeitos" do que eu escrevi; preocupei-me muito mais com a política discursiva dos Araweté, com o complexo regime enunciativo que articula sua vida política, o xamanismo e o ritual guerreiro, que com minha política discursiva para os Araweté.

Retomando a concepção filosófica sobre a multiplicidade, rejeitar um múltiplo que seria feito de muitos uns não é, vale frisar, confinar-se ao um. Ou seja: abrir mão da ideia de compartilhar a autoria entre muitos autores individuais não significa retornar ao pesquisador malinowskiano, heroico e solitário - atributos que derivam um justamente do outro, vale notar. A imagem de etnógrafo a que se reporta pode ser outra, ainda que a tentativa de dissolver a primazia do autor, abrindo espaço para as tramas e os personagens com quem se conviveu (cf. SZTUTMAN, 2006) não precise de modo algum ser abandonada de saída. Lembre- 
se aqui do que escreveu Gregory Bateson (1972: 108): o primeiro passo "em qualquer estudo antropológico é entregar-se aos dados"5.

O que significa, então, fazer uma etnografia que surja de, em não irrelevante parte, algo maior que uma unidade e menor que um todo? Ou, dizendo de outro modo ainda, diferente de ambos? Trata-se de tentar uma experiência que difira daquela do autor singular, já que este não compõe mais uma imagem de autenticidade, tendo perdido seu efeito persuasivo (STRATHERN, 1991: 11). Parece que é a própria necessidade de optar por um modelo que deve ser colocada em xeque, já que os diferentes locais etnográficos, de acordo com Strathern (1991: 24), permitem experienciar-se a si mesmo como diferentes pessoas. Como a mesma autora sintetiza em outro momento: nesse caso, um é pouco, mas dois já é demais (STRATHERN, 1992: 36). A constatação de que se é ligeiramente superado por aquilo que se busca fazer (cf. LATOUR, 1996), inclusive, não parece nem um pouco estranha ao mundo das religiões de matriz africana no Brasil: nas palavras da mãede-santo e antropóloga Gisèle Binon-Cossard, que se pode reconhecer em Fichte (1987: 73): “Existe em nós uma força que pode ser exaltada de tal forma que as pessoas superam a si mesmas."

\section{Reflexividade}

Desta complexa relação entre pesquisadores e pesquisados surgem algumas ideias a respeito dos saberes com que se trabalha. Antes de tudo, é o caso de recusar ao discurso do antropólogo uma vantagem estratégica sobre o discurso do nativo (VIVEIROS DE CASTRO, 2002: 115): de outro modo, a experiência etnográfica estaria ameaçada, se se imaginasse que o papel do etnógrafo seria o de desautorizar o pensamento daqueles com quem convive. Para usar os termos de uma chamada etnometodologia, sugere-se então que, assim como o antropólogo, as pessoas dispõem de um vocabulário e uma teoria social completos para entender o seu comportamento (LATOUR, 2005: 49 nota 46). A importância de afirmá-lo talvez seja ainda maior quando se tem em mente uma narrativa da qual por muito tempo as religiões de matriz africana fizeram parte, tendo em vista o passado das pesquisas nesse campo - estudos empreendidos por "alopatas" os mais diversos, diagnosticando ora doenças mentais, ora raças, culturas, sociedades (SERRA, 1995: 185). Como o mesmo autor afirma em outra obra (1978: vii): “[O]s pontos obscuros e equívocos no quadro aqui traçado devem imputar-se a nós, e jamais à

\footnotetext{
${ }^{5} \mathrm{O}$ termo aqui traduzido com a forma "entregar-se" no original em inglês é surrender, que carrega consigo os sentidos adicionais e igualmente relevantes de "se render", "renunciar", "capitular".
} 
'incoerência' ou à 'falta de lógica', ou à 'imprecisão de pensamento' tantas vezes atribuídas, com absoluta injustiça, ao povo do Candomblé".

As opacidades inevitáveis à compreensão antropológica (ROSALDO, 1980: 47) não só se atribuem ao desconhecimento inicial decorrente do choque cultural que é condição para o trabalho de campo como à própria percepção de que, via de regra, quem controla a informação disponível ao etnógrafo são os nativos (CLIFFORD, 1983: 146). Não se trata aqui de simples inversão da posição de sábio agora recusada ao antropólogo, como se fosse absolutamente impossível o acesso a um conhecimento esotérico, mas sim da constatação de que, por definição, é o saber nativo que interessa ao antropólogo. Se alguma desigualdade há, então, ela não é proibitiva mas sim potencializadora, e não é de ordem, mas de grau: costumeiramente, aprende-se muito mais com os nativos do que eles com o antropólogo (EVANS-PRITCHARD, 1937: 247) - e certos nativos, por vezes, podem aprender menos ainda, como no caso de determinados cientistas (LATOUR, 2005: 100). Os efeitos dessa diferença são também conhecidos pelos próprios coletivos nativos, que tentam, por vezes mesmo em vão, explicar ao antropólogo algo que eles acham que ele muito possivelmente não conseguirá entender, tomando o cuidado, se for possível e desejável, de fazê-lo de maneira generosa (quando a relação e a pesquisa vão bem) para que a comunicação se estabeleça de modo minimamente satisfatório.

Constatada a presença da reflexividade, deve-se franzir o modelo, indicando que nem todas as pessoas são reflexivas do mesmo modo, e que muitas podem mesmo demonstrar pouco ou nenhum interesse em enunciar reflexões sofisticadas, sobretudo quando conversando com um antropólogo. É de pouca valia tanto pensar que nenhum nativo possua reflexividade quanto imaginar que todos desejam fazer reflexões como as do antropólogo. Assim, aquilo que os nativos "não entendem" não pode nem ser ignorado por completo (CLIFFORD, 1981: 233), nem ser transformado em princípio explicativo oculto aos olhos de todos menos aos do antropólogo (LATOUR, 2005: 50, 57).

Por outro lado, e simultaneamente, não é nada impossível, nem mesmo improvável, que os nativos se interessem por aquilo que o antropólogo realiza. Quanto a esse aspecto, Clifford (1981: 244) é enfático: "É condescendente e falso afirmar que apenas o etnógrafo ganha conhecimento sobre os costumes a partir das colaborações do trabalho de campo, ou que os textos e interpretações assim constituídos são significativos apenas para o autor da eventual etnografia." Assim sendo, há grande interesse em se discutir as ideias em jogo com os próprios nativos, o que só pode ser feito de modo bem-sucedido ao se tratar ambos os saberes como disponíveis num mesmo plano de conhecimento. Desta forma, e tendo sorte, o 
antropólogo fará parte de um processo - que ele em alguma medida provoca, mas de modo algo indeterminável - que pode levar os nativos a outras reflexões a respeito de si mesmos (WAGNER, 1975: 7 e nota 1; CLIFFORD, 1981: 234; CLIFFORD, 1983: 139). Como indica Sanjek (1990: 247), o importante é não afunilar as explicações cedo demais.

Fica claro, de toda maneira, que são os nativos que decidem, de acordo com seus interesses, o que revelar ou não ao antropólogo (VIVEIROS DE CASTRO, 1992: 179; STRATHERN, 1999: 9). Constatada a plenitude da reflexividade nativa, vale voltar a marcar que não é sempre de seu interesse formular oralmente aquilo que sabem de um modo que o antropólogo considere satisfatório ${ }^{6}$ (LATOUR, 2005: 4). Afinal de contas, de ordinário os nativos têm mais a fazer do que transcorrer sua existência agradando antropólogos, ainda que isto também possa vir a ocorrer em determinados contextos, cuja explicitação nesse caso precisa ser parte da descrição etnográfica, não tomada como pressuposto. Quando se encontra em tal situação, é o caso do antropólogo, como de costume, não de descartar aquilo que está sendo dito, mas de conservá-lo cum grano salis. Tomadas essas medidas, tornase verossímil encontrar um meio de propor uma reformulação de saberes, de modo a permitir que sejam rearticulados por outrem. Em geral, isto significa produzir um texto que dê a chance a outras pessoas que não tiveram a mesma vivência que o etnógrafo tomarem contato com algo que os nativos compreendem perfeitamente bem.

\section{Convivência}

A importância, então, da participação no fazer antropológico reaparece como fundamental para a prática do trabalho de campo. Se há inovação no método proposto por Malinowski, esta reside na adição do qualificativo "participante" à prática de observação, uma das marcas da antropologia, como lembra George Stocking (1983: 70):

[O trabalho de campo] ao mesmo tempo distingue a disciplina, qualifica seus investigadores, e cria o corpo primário de dados empíricos. [... O trabalho de campo por observação-participante, preferencialmente num grupo social face-a-face bastante diferente daquele do investigador, é a marca da antropologia social/cultural.

\footnotetext{
${ }^{6}$ Há mesmo quem afirme que a exigência de ordem, exemplificada pelos quadros classificatórios de Durkheim e Mauss, é necessidade exclusiva do etnógrafo, não dos atores (GOODY, 1977: 58).
} 
Daí a reserva, por exemplo, da sociologia de Pierre Bourdieu (1980: 56-57) com o método em questão, afirmando, por exemplo, que a observação participante é uma contradição (não só em termos, teoricamente, como impossível de ser praticada): para esse autor, o etnólogo só teria uma participação primitivista ou mística, estando excluído da realidade das práticas sociais, em função de nela tomar parte somente por escolha e como jogo.

Antropólogos em geral discordam dessa afirmativa. Sua relação com os nativos não é considerada como mero "jogo", já que o trabalho de campo deve, por definição, afetar o pesquisador "[S]eus problemas são aqueles dos povos que estuda - problemas postos por estes povos para si mesmos, e portanto para os antropólogos", concatena Viveiros de Castro (1992: 177, ênfase adicionada). Para isto, faz-se necessária uma postura específica, que considere a importância da vivência antropológica no campo em si - ainda que ele só passe a existir, enquanto tal, retrospectivamente, depois de terminado o processo de registro etnográfico (CRAPANZANO, 1977: 70; STRATHERN, 1999). Não se trata simplesmente, adverte-se, da busca do estabelecimento de rapport, já que não há nada inerentemente benigno na socialidade por si só, e ela não pode servir como desculpa para se obter uma percepção mais relevante (STRATHERN, 1991: 46). Relações são importantes justamente porque relacionam, porque colocam em relação (VIVEIROS DE CASTRO, 2002: 129).

O caso, então, é quase o de dizer que o que deve ser instrumentalizado é o conhecimento, não a oportunidade de relacionar7. Strathern (1999: 9) resume-o, lembrando também que são as pessoas que decidem tornar ou não o antropólogo parte de suas relações umas com as outras: "É de trás para a frente imaginar que isto pode ou deve ser empreendido de modo a coletar dados melhores. As relações precisam ser valorizadas pelo bem delas próprias." A informação resultante, prossegue a autora, é efeito residual desse processo. Nessa chave podem ser lidas as afirmações de antropólogos que consideram como constitutivas as relações emocionais estabelecidas com as pessoas com as quais conviveram (p. ex. VIVEIROS DE CASTRO, 1992: 180; KULICK, 1998, SOUTY, 2007: 85), assim como é possível valorizar uma experiência anterior que não tenha tido por horizonte um trabalho acadêmico (SERRA, 1978: vi). Daí também o sem número de antropólogos que contam com verdadeiros amigos, parentes, ou mesmo amantes entre os "seus" nativos - e aqui o pronome possessivo adquire outro sentido. Ilustra-o uma passagem de um estudo envolvendo candomblé:

\footnotetext{
${ }^{7}$ Aponte-se que subtrair é também um modo de se colocar em relação, cf. Strathern (1991).
} 
Eu me perguntei por que parece importante incluir essa pequena cena desconexa em meu capítulo conclusive. Acho que é porque até aquele momento eu tinha esperado que seria um alívio estar longe das pressões "do campo". Mas no bar de Felipe eu percebi que Jaraci não era "o campo" no sentido antropológico. Tinha se tornado minha "terra". .8 (WAFER, 1991: 177).

Tampouco se trata de se aproximar do nativo tendo como meta sua conversão, ainda que uma relação assim estabelecida possa obter resultados específicos, como era o caso de Maurice Leenhardt, de acordo com Clifford (1981: 230, 233-234) - e o termo "conversão" aqui não se limita à religiosa. Pouco adianta, também, dizer que é impossível pertencer simultaneamente ao dentro e ao fora, refugiando-se numa "antropologia teológica" (ou teologia antropológica, como em Juana Elbein dos Santos (1975: 18) - ainda que esse caminho não seja destituído de interesse -, já que se considera aqui que a questão não é tanto de pertencimento a uma classe como de participação em uma relação. Por fim, a observação participante não significa, tampouco, uma improvável metamorfose em nativo 9 : trata-se de uma condição de possibilidade para captar ações e discursos em ato (GOLDMAN, 2006: 170).

Na relação que antropólogo e nativos entretêm, é crucial considerar também a dimensão de troca envolvida. Como sugere Clifford (1986: 9), a caricatura do cientista social ambicioso, que se aproveita do saber nativo sem oferecer nada por ele, impondo retratos toscos a povos sutis ou sendo enganado por informantes sofisticados, é não só negativa como bem pouco realista. Assim, e do mesmo modo como Lévi-Strauss (1955: 291) em sua relação com o chefe tarundê, não se concebe o trabalho etnográfico como unilateral, mas como envolvendo prestações. Um dado deve, justamente, ser algo dado: pragmaticamente, em circunstâncias que $a$ priori não se pode abstrair. De seu processo de obtenção, inclusive, não deveriam fazer parte estratégias propondo arrancar a informação a qualquer preço, como parecem exemplificar, por vezes, os métodos de Marcel Griaule e Nicholas Miklouho-Maclay (CLIFFORD, 1983: 132-134; STOCKING, 1991: 17, 20). Os discursos devem ser, de algum modo e apropriadamente, suscitados em conversação (SANJEK, 1990: 211-212; STRATHERN, 1991: 7-8): a ideia é evocação,

\footnotetext{
${ }^{8}$ Não é aqui o local senão de indicar brevemente que a terra é um elemento, em mais de um sentido, prenhe de significados para o povo-de-santo (cf. BANAGGIA, 2018).

9 Tentativa que pode mesmo ser ridicularizada pelos próprios nativos, como no episódio protagonizado por Sol Tax em que, para seguir o método etnográfico malinowskiano ideal, o antropólogo iniciou seu trabalho de campo indo viver num acampamento em meio aos índios fox: os nativos comentaram, com certo desdém bem-humorado, que não fazia sentido Tax cozinhar para si mesmo, como é comum uma mulher fazer, quando poderia facilmente ir até a cidade, bastante próxima, para fazer suas refeições (relatado em STOCKING, 1983: 111).
} 
não provocação.

Levar em conta os processos de troca, além disso, faz muito sentido quando se considera que a transmissão é um fenômeno muito enfatizado pelos sistemas cosmológicos e rituais das religiões de matriz africana, sendo o conhecimento adquirido em função de, entre outras coisas, amizade recíproca (BASTIDE, 1958: $64,25)$. Como contrapartida pelo recebimento da informação, pode mesmo caber ao antropólogo efetuar o pagamento em outra moeda, prestação na qual, de modo não incomum, algum dispêndio financeiro pode estar implicado. Ainda que se critique, de modo geral e não infundamentado, o uso de informantes pagos, desejando-se a substituição do paying pelo rapport (SANJEK, 1990: 228), há de se pensar que, por vezes, essa distinção pode não ser tão significativa. Roger Bastide merece ser citado em sua extensão:

A informação é um dom que, como todos os outros, necessita de um contradom, sem o qual haveria uma ruptura nas relações sociais e até mesmo no mundo. O contradom que, nesses candomblés, não é quase nunca dinheiro propriamente dito, mas um pedaço de tecido, um animal que será oferecido em sacrifício, um colar etc., compensa a perda de substância, se assim se pode dizer, daquele que ofertou uma parte do "segredo" e restabelece o equilíbrio perdido. Porém, se o contradom é um animal, o pesquisador fica ligado ao orixá, que pode então puni-lo se empregar mal o conhecimento obtido, ou pode dar-lhe a permissão de utilizar esse conhecimento (uma vez que ele, orixá, também recebeu com o sacrifício o seu contradom) [...]. (1958: 64-65, ênfase adicionada).

O saber no candomblé é intrinsecamente valioso, não podendo ser concedido de forma gratuita. Daí haver especial interesse em se prestar atenção aos atos falhos, às demonstrações ostentatórias, às trocas. Não porque, com isso, o antropólogo encontre um meio de ser mais astuto que o povo-de-santo, mas sim por ser esta a forma pela qual permanecerá mais próximo do modo pelo qual o conhecimento é transmitido de acordo com os preceitos dessa tradição religiosa. Isso quer dizer, por exemplo, que práticas de transmissão de saber culturalmente específicas que a antropologia apreende em determinados contextos podem ser realocadas para pesquisas em situações distintas daquela que as originou, desde que sejam feitas as transformações (no dizer de LATOUR, 2005: 106 e ss., ou seja, as traduções/translações) necessárias a esse objetivo. Para lidar com um exemplo concreto: compreender que transmitir saber nas religiões de matriz africana significa transmitir igualmente uma dada substância (no caso o axé, que tem entre seus muitos sentidos o de "força vital") transforma a apreensão e as práticas na própria pesquisa em relação ao aprendizado: ao que exatamente se transfere 
quando alguém aprende, ao tipo de vínculo que se estabelece entre as pessoas nessa relação, e ao que uma parte deve à outra em função desse processo (BANAGGIA, 2015: 168, 222-223).

A relação que se constitui entre antropólogos e interlocutores não é, como já se mencionou, isenta de conflitos. Ao contrário, considera-se um certo choque etnográfico como próprio da experiência com a diferença, como visto, por exemplo, em Malinowski (apud GEERTZ, 1988: 73), Roy Wagner (1975: 6-7) e Vincent Crapanzano (1977: 69). Não obstante, há uma distinção entre o choque e a agressão, esta considerada incontornável por outras propostas: é o caso da violência inevitável em Rabinow (apud GEERTZ, 1988: 98), da violência irredutível e das dissimulações táticas em Clifford (1983: 142) ou mesmo delineada pelo assalto físico em Malinowski, de acordo com Stocking (1983: 100). Se não há motivo para negar a existência de certo grau de violência nessa relação, por outro lado, quando ela existe, é muitas vezes o etnógrafo que a sofre (LÉVI-STRAUSS, 1955: 53), e não necessariamente em função de premeditação por parte das pessoas com quem convive. Afinal de contas, o antropólogo, como se depreende da experiência desterritorializante de Binon-Cossard (apud FICHTE, 1987: 78, em especial), por vezes não sabe mais a que mundo pertence - se é que alguma vez já pertenceu, acrescentar-se-ia, talvez, com Lévi-Strauss (1955: 53). Para o estudo em questão, note-se, além disso, que se recusar a lidar com uma dimensão propriamente violenta presente no candomblé significa aproximar-se da atividade repressiva típica não do antropólogo mas do Estado (CARVALHO, 1994).

A única forma que aqui se vê de encontrar, então, algo assemelhado à postura teatral e irônica que Clifford (1983: 143) elogia em Griaule é abdicar da mencionada sugestão bourdiana de jogar o jogo só a partir de uma posição semicomprometida. O que se percebe é a existência de uma forma de conduta continuamente afetada por um conjunto de três disposições: pela ironia, pela objetividade e pela resistência, em sentidos bastante específicos. Ironia porque, de acordo com Donna Haraway, como visto em Strathern (1991: 35), refere-se a contradições que não se resolvem, nem mesmo dialeticamente, em todos mais abrangentes; a ironia indica uma tensão constitutiva, uma compatibilidade profícua, proficiente. Objetividade porque, para Latour (2005: 124-125, 129), rastreiam-se objetos que têm a oportunidade de apresentar objeções àquilo que deles se diz, com um texto no qual os atores não deixam de ter a capacidade de levar outros a fazer coisas inesperadas. Resistência porque, segundo Fabian (1983: 33), filosoficamente falando, é a continuidade do trabalho de campo como ferramenta antropológica que garante $\mathrm{o}$ caráter que ele denomina aporético da etnografia na antropologia. Em suma: 
[O] nativo certamente pensa, como o antropólogo; mas, muito provavelmente, ele não pensa como o antropólogo. O nativo é, sem dúvida, um objeto especial, um objeto pensante ou um sujeito. Mas se ele é objetivamente um sujeito, então o que ele pensa é um pensamento objetivo, a expressão de um mundo possível, ao mesmo título que o que pensa o antropólogo. (VIVEIROS DE CASTRO, 2002: 119, ênfases no original).

\section{Duração}

Essa postura ao mesmo tempo metodológica e epistemológica de convivência em profundidade na pesquisa não oferece resultados de modo veloz. Realmente, há recomendações expressas para que o trabalho de campo seja uma empreitada de longa duração (MEAD, 1933: 7; EVANS-PRITCHARD, 1937: 252; SANJEK, 1990: $189,195)$. Diz-se mesmo que é só depois de um período consideravelmente longo de convívio em campo que se passa a perceber o próprio alcance daquilo que se ignora, sendo necessário um tempo longo para se colocar em questão percepções anteriores (CLIFFORD, 1981: 227, 245). Fundamentais são também os intervalos e os retornos ao campo, para que a frequência das estadas possa fazer justiça à dinâmica característica do mundo vivido. Comenta Clifford:

O tempo etnográfico é muito frequentemente de outro tipo: controlado, linear, com o pesquisador "coletando" dados, em vez de "produzi-los" em colaboração com os informantes. No fundo, o trabalho de campo requer uma certa cumplicidade (um termo melhor, talvez, que rapport). Mas cumplicidade não é reciprocidade, embora possa ser parte da reciprocidade. Uma pergunta desencadeia a troca; uma resposta institui uma dívida. $\mathrm{O}$ contínuo processo de dom e contradom obedece a ritmos regulares, um tempo que nem sempre sincroniza com o calendário acadêmico ou com a duração dos recursos da pesquisa. A resposta a uma pergunta pode vir décadas depois. $(1981: 247)^{10}$.

Ao se ignorar os procedimentos necessários a uma slow-ciology, no dizer de Latour (2005: 123-124, 156), aumenta-se a chance de se imaginar ser preciso recorrer ao uso da força para "extrair" informação. Distancia-se aqui do exemplo de Griaule, como visto em Clifford (1983: 132-134), que via por bem incitar seus nativos, confundindo-os e mesmo desrespeitando-os, a ponto de, por exemplo, exumar sepulturas sagradas em sua afoiteza por conhecimento. Este artigo procura se alinhar em alguma medida então com Evans-Pritchard (1937: 243, 248, 252) que,

${ }^{10}$ Sobre o rendimento dessa cumplicidade produtiva, ver também Clifford (1983: 144). 
ao seguir o conselho de Alfred Haddon - impelindo-o a simplesmente se portar como um cavalheiro quando fosse ao campo -, recomendava fazer o possível para não se ser inoportuno nem criar constrangimentos para os nativos.

A burilada desapressada no fazer etnográfico, tanto no campo como no texto, e na medida do possível, apresenta-se então como técnica notadamente valiosa, e em consonância com os preceitos das religiões de matriz africana como o candomblé (ELBEIN DOS SANTOS, 1975: 18; SERRA, 1978: vi). Como indica Bastide (1958: 25), "é o tempo que amadurece o conhecimento das coisas; o ocidental quer saber de tudo desde o primeiro instante, eis por que, no fundo, nada compreende". Buscase, assim, manter certa continuidade entre a forma de se aprender e de se transmitir conhecimento tanto no candomblé quanto na pesquisa sobre ele: e essa forma é lenta, com o conhecimento se entranhando pouco a pouco (GOLDMAN, 2005: 106107). De que outro modo poderia um antropólogo vir a tomar ciência de premeditações como as que indica Binon-Cossard (1970), como a prática de adicionar a um preparo místico outras ervas além das comumente necessárias, que não possuem efeito algum senão o de ludibriar observadores indesejados, ávidos por adquirir conhecimento11 ${ }^{11}$ Goldman (2005: 108-109, ênfase adicionada) sumariza-o:

O que se deve aprender não é conceptualizado como um corpo perfeitamente coerente e unificado de regras e conhecimentos, como algum tipo de doutrina sobrecodificada e imposta de cima. Aquele que deseja aprender alguma coisa no candomblé sabe muito bem, e desde o início, que é inútil esperar ensinamentos prontos e acabados de algum mestre, e que deve tratar de ir reunindo, pacientemente, ao longo dos anos, os detalhes que recolhe aqui e ali, com a esperança de que, em algum momento, esse conjunto de saberes adquira uma densidade suficiente para que com ele se possa fazer alguma coisa.

Sabe-se que não há, do ponto de vista da universidade, como contornar por completo os gravames e prazos provenientes de constrições acadêmicas, como já se mencionou, mas o que se sugere aqui é que, especialmente neste caso, a falta não pode ser transformada em virtude: não é por não se ter tempo suficiente que o pesquisador deve recorrer a uma explicação última e toda poderosa que facilite seu trabalho. Almeja-se o pequeno, o "um passo de cada vez", algo que resulte em uma contribuição do tamanho que se lhe couber; até porque, como indicam as palavras da expoente do candomblé angola Valdina Pinto, "[s]ó se é realmente grande quando se sabe ser pequeno." (PINTO, 1997: 63, ênfases no original). Assim, o caso

${ }^{11}$ Ou seja: trata-se de um efeito e tanto. Cf. tmb. Fardon (1990: 28). 
é o de não cortar os estudos (e a etnografia) cedo demais, oferecendo explicações à complexidade que não se foi capaz de abarcar, mas descrever de modo vivaz, o melhor que for possível, e até onde se for capaz de chegar.

\section{Descrição}

É deste modo que as orientações desenvolvidas neste artigo pretendem auxiliar a tentativa de dar conta da dimensão cotidiana, inconspícua, nem sempre explicitada ritualmente das práticas tradicionais (MEAD, 1933: 2, 4), que é igualmente fundamental também para o estudo da liturgia do candomblé (SERRA, 1995: 188). Assim, a forma de se registrar a experiência etnográfica, frequentemente, ainda que não forçosamente, em um texto escrito, não deve emergir incólume da própria observação participante (CLIFFORD, 1986: 2-3). A descrição a que se aspira, todavia, é resultado de procedimentos antropológicos específicos, como foi visto até o momento, e ela tem por finalidade apreender a diferença "sem suprimi-la, pensá-la em si mesma, como ponto de apoio para impulsionar o pensamento, não como objeto a ser simplesmente explicado" (GOLDMAN, 2006: 164). Para apreciar a crítica de Strathern (1991: 9) em relação às disjunções entre pesquisador de campo, escritor e autor, há de se saber quais as relações específicas que se tem com o campo, com a audiência pretendida, com a mensagem a ser transmitida. Descrever as pessoas e o mundo que habitam, de modo objetivo, é não só possível como desejável, desde que dessa forma se permita tornar visíveis os encontros etnográficos em vez de ocultá-los (EVANS-PRITCHARD, 1937: 255; VIVEIROS DE CASTRO, 2002: 126; CLIFFORD, 1983: 124).

Ressalve-se que buscar uma descrição etnográfica não pode, de todo modo, servir como desculpa para se escrever textos de má qualidade, questão que assola os antropólogos (PRATT, 1986: 33). Funções expressivas e "retóricas" não podem ser meras decorações ao texto antropológico, como se este fosse considerado científico por si só, independentemente da forma como é escrito (CLIFFORD, 1986: 4). A arte antropológica, neste sentido, consiste em fabricar habilmente artefatos úteis ao processo descritivo (CLIFFORD, 1986: 6), atividade que vai ao encontro do intento de se fazer bons registros, ao mesmo tempo precisos, fiéis, interessantes, objetivos (LATOUR, 2005: 126-127). Com Latour (2005: 127), recorda-se que há sempre o risco de um experimento não dar certo, perigo que parece passar despercebido pelos advogados pós-modernos da autossuficiência textual.

Estabelecida a importância de se buscar continuidade entre o objeto de investigação e o modo de se configurar o relato da experiência - como, por exemplo, Clifford (1983: 144) afirma haver nos trabalhos tardios de Marcel Griaule 
com Germaine Dieterlen, em que a metáfora organizacional comum é a da "iniciação" -, note-se que também neste tema não há substituição do discurso do antropólogo pelo discurso do nativo: o modo descritivo do etnógrafo deve tentar acompanhar parcialmente as estratégias de disposição discursiva e de transmissão de conhecimento que as pessoas com quem convive utilizam (GOLDMAN, 2005: 109). Descrever não significa, assim, repetir o discurso nativo, e tampouco ignorálo tendo em vista a revelação de princípios ocultos que lhe sobredeterminariam: a antropologia se move, enfim, "[e]ntre a noção objetivista de uma realidade última a que apenas nós temos acesso e saber [...] e a hipótese idealista de que qualquer coisa que digamos não passa de crença" (GOLDMAN, 2006: 166).

O ponto de vista do antropólogo, conclui-se, não se confunde com o ponto de vista do nativo, mas emerge de sua relação com ele, algo que envolve uma dimensão essencial de ficção, já que em ressonância estão dois pontos de vista distintos (VIVEIROS DE CASTRO, 2002: 122-123). Pensando com os termos de Latour (2005: 39), o caso parece ser o etnógrafo fazer com a diferença o papel de mais um mediador, não de um intermediário, ou seja, necessariamente transformando um conteúdo ao transportá-lo. No modo como escreve Goldman (2005: 169), “o antropólogo não é nem o cientista cujas teorias transcendem a experiência que ele decidiu partilhar, nem apenas mais um narrador a acrescentar seu relato a todos os demais". Subvertendo ligeiramente a posição de Malinowski, como colocada em Geertz (1988: 77) de que a apreensão do exótico se daria nas imediações do encontro, dir-se-ia que a percepção da diferença se dá nas mediações que são a partir dele efetuadas. De certo modo, então, o caso seria o de o antropólogo transmitir, traduzir, transladar uma diferença diferente da diferença que experimentou em sua convivência com os nativos ${ }^{12}$.

\section{Discrição}

A título de arremate, oferece-se a indicação de que o ímpeto descritivo também não deixa de reconhecer momentos de interrupção. Afinal, sempre há perguntas que não podem ser feitas, ou ao menos não devem ser feitas de qualquer modo - como perguntar a um nuer quantas cabeças de gado possui, segundo Evans-Pritchard (1937: 248). Todavia, há de se distinguir entre uma resposta que não desperta interesse por ser em si desinteressante na situação do encontro e aquela que não pode ser respondida por outros motivos, como uma sobre a qual se deve calar em

12 Esta síntese apoia-se especialmente em Strathern (1991: 37), Viveiros de Castro (2002: 113-114), Latour (2005: 108); não necessariamente nesta ordem. 
função da imposição do segredo, por exemplo (SOUTY, 2007: 48, 385-401). Em relação ao candomblé, como já se deve ter notado, há impedimentos para se obter certos saberes, em especial em relação aos procedimentos rituais, mas mesmo informações a respeito da mitologia, já que, depois de oferecidas, podem ser usadas contra quem as concedeu (BASTIDE, 1958: 25). Assim, por exemplo, uma das primeiras coisas que se aprende na vivência em religiões de matriz africana é que perguntar a alguém de modo direto qual é sua principal entidade protetora nunca é considerada uma indagação feita inocentemente, quer a pessoa o saiba, quer não. Como indagar a esse respeito gera no mínimo curiosidade quando não imediata estranheza nesse contexto, o antropólogo que aprende essa lição torna-se capaz de mobilizá-la também em outros momentos e em outras situações de pesquisa, aprimorando o próprio método acadêmico.

Cautela, porém, não significa paralisia: é sempre com alguma prudência que se é possível prosseguir. Na prática, o fato de haver uma lógica de segredo não invalida de modo algum a pesquisa; sua existência como dimensão constitutiva do universo vivido, bem pelo contrário, pode levar a importantes percepções, como se apontará adiante. Diga-se que uma certa medida de confrontamento existe, mas que, do mesmo modo como sugerem Latour e Woolgar (1979: 177 nota 7) para os cientistas, uma agonística nem sempre significa uma antagonística tão pronunciada como se pensa: no candomblé não há problema em se dizer que algo não pode ser dito, e mesmo a condição de que algo não pode ser revelado pode ser colocado em contenda (Vários 1997: 34). Assim, cabe a cada antropólogo, tanto quanto for capaz, guiar-se por essas diretrizes.

Por vezes, então, e de acordo com as circunstâncias, já indicar que há o segredo e que sua existência leva as pessoas a fazerem ou deixarem de fazer certas práticas é uma forma de persistir no registro do encadeamento das associações dispostas pelos próprios atores (LATOUR, 2005: 137, 147). Segredos, percebe-se sem exagero, por definição só existem enquanto não desvendados, e é em função de seu ocultamento que têm lugar na mise en scène social (CLIFFORD, 1983: 147 nota 4). A retórica antropológica a que aqui se aspira, então, é uma que se fortalece graças a sua parcialidade subversiva (CLIFFORD, 1986: 6), potencializa-se ao deixar de fora aquilo que não é feito para ser público (FICHTE, 1987: 76). Descreve-se melhor ao se perceber que o mistério é inesgotável do que ao tentar dilapidá-lo reduzindo-o ao que quer que seja. Na colocação de Clifford (1986: 7): “[T]odas as verdades construídas são tornadas possíveis por poderosas 'mentiras' de exclusão e retórica. Mesmo os melhores textos etnográficos - ficções sérias, verdadeiras - são sistemas, ou economias, de verdades".

Há mais. É possível compreender os mecanismos de articulação dos saberes de 
modo similar ao que faz Strathern (1991: 96-97) com a avaliação de Fredrik Barth: diferentemente deste, a autora entende a perda de conhecimento como parte da informação, não como perda de informação. A economia de verdade que envolve o segredo, assim, é parte dos dados da pesquisa, não uma impossibilidade de acessá-los. Ao mesmo tempo, se o modelo gerativo de Barth revolvido pela autora explicita a "procriatividade" da falta e da perda, o modelo iniciático do candomblé, de certo modo, evidencia a lentidão do aprendizado e a repartição do conhecimento. Se, para os anciãos baktaman a que se referem esses autores, a imagem da perda de saber põe em primeiro plano um saber a respeito da falta, do esquecimento e da irrecuperabilidade (STRATHERN, 1991: 97-98), para o povo-desanto o fato de haver segredo quanto ao saber é índice de um saber sobre o sigilo, a ocultação, a discrição - e daí sobre os valores tanto da modéstia quanto da ousadia nas manipulações e experimentações.

Permite-se assim terminar este artigo com a esperança de que ele possa ser fonte de uma luz forte ao mesmo tempo que parcial (CLIFFORD, 1986: 21). Afinal, e para retornar à epígrafe que o pôs em movimento, a luz plena pode se mostrar inimiga da perspectiva. Espera-se que uma réstia difusa, cambiante, vacilante por vezes, possa ser de alguma valia no estudo de planos em permanente complexificação. Que ela possa ser útil na criação de etnografias que funcionem melhor quando vislumbradas de modo indireto, por uma luz, quem sabe, como a do crepúsculo.

\section{Referências}

BANAGGIA, Gabriel.

(2015). As forças do jarê: religião de matriz africana da Chapada Diamantina. Rio de Janeiro: Garamond.

(2018). Canalizar o fluxo: lidando com a morte numa religião de matriz africana. Mana: estudos de antropologia social, 24 (3), pp. 9-32.

BASTIDE, Roger.

(1958) [2005]. O candomblé da Bahia: rito nagô. São Paulo: Companhia das Letras.

BATESON, Gregory.

(1972) [2000]. Steps to na Ecology of Mind. Chicago, London: University of Chicago Press.
BINON-COSSARD, Gisèle.

(1970). Contribution à l'Étude des Candomblés du Brésil: Le Rite Angola. Tese de Doutorado. Paris: Sorbonne.

BOURDIEU, Pierre.

(1980). Le sens pratique. Paris: Minuit.

CARVALH0, José Jorge de.

(1994). Violência e caos na experiência religiosa: a dimensão dionisíaca dos cultos afro-brasileiros. In: MOURA, Carlos Eugênio Marcondes de (org.). As Senhoras do pássaro da noite: escritos sobre a religião dos orixás V. São Paulo: AM, Edusp, pp. 85-120. 
CLIFFORD, James.

(1981) [1998]. Trabalho de campo, reciprocidade e elaboração de textos etnográficos: 0 caso de Maurice Leenhardt. In: $A$ experiência etnográfica: antropologia e literatura no século XX. Rio de Janeiro: Editora UFRJ, pp. 227-251.

(1983). Power and Dialogue in Ethnography: Marcel Griaule's Initiation. In: George W. Stocking, Jr. (ed.). Observers Observed: Essays on Ethnographic Fieldwork. Madison: The University of Wisconsin Press, pp. 121-156.

(1986). Introduction: Partial Truths. In: James Clifford \& George E. Marcus (eds.). Writing Culture: the Poetics and Politics of Ethnography. Berkeley, Los Angeles, London: University of California Press, pp. 1-26.

CRAPANZANO, Vincent.

(1977). On the writing of ethnography. Dialectical Anthropology, vol. 2, n. 1, pp. 69-73.

ELBEIN DOS SANTOS, Juana.

(1975) [2002]. Os Nàgô e a morte: Pàde, Àsèsè e o culto Égun na Bahia. Petrópolis: Vozes.

EVANS-PRITCHARD, Edward Evan.

(1937) [2005]. Bruxaria, oráculos e magia entre os Azande. Rio de Janeiro: Jorge Zahar Editor.

FABIAN, Johannes.

(1983). Time and the Emerging Other. In: Time and the Other: How Anthropology Makes Its Object, pp. 1-35.

FARDON, Richard.

(1990). Localizing Strategies: The Regionalization of Ethnographic Accounts. In: Richard Fardon (ed.). Localizing Strategies: Regional Traditions of Ethnographic Writing. Edinburgh: Scottish Academic Press \& Washington: Smithsonian Institution Press, pp. 1-35.

FERRARI, Florencia.

(2006). Como estudar nômades com um pensamento nômade? Sugestões para definir um campo em antropologia. Disponível em: https://sites.google.com/a/abaetenet.net/nan si/abaetextos/como-estudar-n\%C3\%B4madescom-um-pensamento-n\%C3\%B4madesugest $\%$ C3\%B5es-para-definir-um-campo-em- antropologia-florencia-ferrari. Acesso em: 25 nov. 2019.

FICHTE, Hubert.

(1987). Etnopoesia: antropologia poética das religiões afro-brasileiras. São Paulo: Brasiliense.

GEERTZ, Clifford.

(1973). Deep Play: Notes on the Balinese Cockfight. In: The Interpretation of Cultures. New York: Basic Books, pp. 412-442.

(1988). I-Witnessing: Malinowski's Children. In: Works and Lives: The Anthropologist as Author. Stanford: Stanford University Press, pp. 73-101.

GOLDMAN, Marcio.

(2005). Formas do Saber e Modos do Ser: observações sobre multiplicidade e ontologia no Candomblé. Religião \& Sociedade, vol. 25, n. 2, pp. 102-120.

(2006). Alteridade e experiência: antropologia e teoria etnográfica. Etnográfica, vol. X. n. 1, pp. 161-173.

G00DY, Jack.

(1977). The domestication of the savage mind. Cambridge, London, New York, Melbourne: Cambridge University Press.

JACKSON, Jean Elizabeth.

(1990). "I Am a Fieldnote": Fieldnotes as a Symbol of Professional Identity. In: Roger Sanjek (ed.). Fieldnotes: The Makings of Anthropology. Ithaca, London: Cornell University Press, pp. 3-33.

KULICK, Don.

(1998). Travesti: sex, gender and culture among brazilian transgendered prostitutes. Chicago, London: The University of Chicago Press.

LATOUR, Bruno.

(1996) [2002]. Reflexão sobre o culto moderno dos deusesfe(i)tiches. Bauru: Edusc.

(2005). Reassembling the Social. 0xford: 0xford University Press. 
LATOUR, Bruno \& Steve Woolgar.

(1979) [1997]. A vida de laboratório: a produção dos fatos científicos. Rio de Janeiro: Relume Dumará.

LÉVI-STRAUSS, Claude.

(1955) [2005]. Tristes trópicos. São Paulo: Companhia das Letras.

LIMA, Tânia Stolze.

(1999). Para uma teoria etnográfica da distinção natureza e cultura na cosmologia juruna. Revista Brasileira de Ciências Sociais, vol. 14, n. 40, pp. 43-52.

MEAD, Margaret.

(1933). More comprehensive field methods. American Anthropologist. vol. 35, n.1, pp. 1-15.

PINT0, Valdina.

(1997). Candomblé angola. In: Vários autores. II Encontro de Nações de Candomblé. Salvador: Centro de Estudos Afro-Orientais - UFBA.

PRATT, Mary Louise.

(1986). Fieldwork in Common Places. In: James Clifford \& George E. Marcus (eds.). Writing Culture: the Poetics and Politics of Ethnography. Berkeley, Los Angeles, London: University of California Press, pp. 27-50.

RABINOW, Paul.

(1977). Reflections on fieldwork in Morocco. Berkeley: University of California Press.

ROSALD0, Renato.

(1980). Ilongot Headhunting 1883-1974: A Study in Society and History. Stanford: Stanford University Press.

SAHLINS, Marshall.

(1985). Islands of History. Chicago, London: The University of Chicago Press.

(1995) [2001]. Como pensam os "nativos": sobre o Capitão Cook, por exemplo. São Paulo: Edusp.

SANJEK, Roger.

(1990). The Secret Life of Fieldnotes. In: Roger Sanjek (ed.). Fieldnotes: The Makings of Anthropology. Ithaca, London: Cornell University Press, pp. 187-270.
SERRA, Ordep [José Trindade-].

(1978). Na trilha das crianças: os Erês num Terreiro Angola. Dissertação de Mestrado em Antropologia Social - UnB.

(1995). Águas do Rei. Petrópolis: Vozes.

SOUTY. Jérôme.

(2007). Pierre Fatumbi Verger: du regard détaché à la connaissance initiatique. Paris: Maisonneuve \& Larose.

STOCKING, George W., Jr.

(1983). The Ethnographer's Magic: Fieldwork in British Anthropology from Tylor to Malinowski. In: George W. Stocking, Jr. (ed.). Observers Observed: Essays on Ethnographic Fieldwork. Madison: The University of Wisconsin Press, pp. 70-120.

(1991). Maclay, Kubary, Malinowski: Archetypes from the Dreamtime of Anthropology. In: George W. Stocking, Jr. (ed.). Colonial Situations: Essays on the Contextualization of Ethnographic Knowledge. Madison: The University of Wisconsin Press, pp. 9-74.

STRATHERN, Marilyn.

(1987). The limits of auto-anthropology. In: Anthony Jackson (ed.). Anthropology at Home. London, New York: Tavistock Publications, pp. 16-37.

(1991). Partial connections. Savage: Rowman \& Littlefield Publishers.

(1999). The Ethnographic Effect I. In: Property, Substance and Effect: Anthropological essays on persons and things. London: The Athlone Press, pp. 1-26.

SZTUTMAN, Renato.

(2006). Um thriller etnológico na alta Amazônia. Folha de São Paulo. Publicado em 17 de outubro de 2006.

THOMAS, Nicholas.

(1991). Against Ethnography. Cultural Anthropology, vol. 6 , n. 3, pp. 306-322. 
Vários.

(1997). II Encontro de Nações de Candomblé. Salvador: Centro de Estudos Afro-Orientais UFBA.

VIVEIROS DE CASTRO, Eduardo.

(1992). 0 campo na selva, visto da praia. Estudos Históricos, 5 (10), pp. 170-199.

(2002). 0 nativo relativo. Mana: estudos de antropologia social, 8 (1), pp. 113-148.

WAFER, Jim.

(1991). The Taste of Blood: Spirit Possession in Brazilian Candomblé. Philadelphia: University of Pennsylvania Press.
WAGNER, Roy.

(1975) [1981]. The invention of Culture. Chicago, London: The University of Chicago Press.

\section{Recebido em}

novembro de 2019

\section{Aprovado em}

abril de 2020 